\title{
The Economic Value of Transmission Lines and the Implications for Planning Models
}

\author{
Alberto J. Lamadrid ${ }^{\mathrm{a}, *}$, Surin Maneevitjit ${ }^{\mathrm{b}}$, Timothy D. Mount ${ }^{\mathrm{c}}$ \\ ${ }^{a}$ Rauch Business Center 451, Lehigh University, Bethlehem, PA, 18015, United States \\ ${ }^{b}$ Goldman Sachs, London, United Kingdom \\ ${ }^{c}$ Warren Hall B41, Cornell University, Ithaca, NY, 14853, United States
}

\begin{abstract}
Many connections between economic efficiency, regulation, the environment and energy markets are evident in the planning for transmission upgrades in an electricity network. Transmission owners have to make decisions about investing in new assets while facing uncertainty in the generation plans, regulatory and environmental constraints, and current system endowments. In this paper, we demonstrate an analytical method for determining the economic value of individual transmission lines in a meshed network by calculating the total welfare effects for the system. While many regulators believe that traditional congestion rents provide the correct incentives for investing in transmission upgrades, we show that the uncertainty in system conditions breaks down this paradigm. The analysis uses an existing Security Constrained Optimal Power Flow (SCOPF) model and a test network to demonstrate how the method can be used to determine the welfare effects of changing the capacity of selected transmission lines. The results show that a substantial portion of the economic benefits for an individual line may come from maintaining system reliability when equipment failures occur. Furthermore, these benefits can change dramatically when inherently intermittent sources of renewable generation are added to a network, and the changes in benefits are not captured effectively by changes in the expected congestion rents.
\end{abstract}

Keywords:

Reliability, Wind, Security Constrained OPF, Value of Lost Load (VOLL), Adequacy, Congestion Rents.

JEL Classification codes Q48, C63, L94.

\section{Introduction}

On the afternoon of September 8th, 2011, the southwestern United States and Northwestern Mexico areas were immersed in what has been called the Great

${ }^{*}$ Corresponding Author
Email address: ajlamadrid@ieee.org (Alberto J. Lamadrid)

Preprint submitted to Energy Economics

March 14, 2016

(C) 2016. This manuscript version is made available under the Elsevier user license http://www.elsevier.com/open-access/userlicense/1.0/ 
Blackout of 2011. The event, triggered by a tripping line in Arizona, lasted for around 12 hours, curtailing $7890 \mathrm{MW}$ of demand and affecting around 2.7 million people in the US alone (Peevey et al. 2011). The series of cascading events that over 12 minutes culminated in the loss of power highlight some of the challenges for Regional Transmission Organizations (RTOs). While small deviations in frequency are allowed, supply and demand need to be balanced in real time, with the available units committed and ready for dispatch. Given the current sources of uncertainty, RTOs have developed a set of operating practices that imply temporal separation. However, many RTOs will see increased amounts of Renewable Energy Sources (RES) entering their generation fleets in the coming years (EIA, 2014). The main policy question in this case is how to better integrate these stochastic resources, and what are the transmission capacity needs. This in turn requires proper appraisal of the economic value of transmission assets in the system.

The objective of this article is to present an analytical framework to determine the economic value of transmission lines. In particular, we propose a methodology for assessing the economic welfare changes with transmission expansion, in the presence of large sources of uncertainty. This is a situation that is especially important due to the integration of inherently intermittent sources of generation (e.g., wind capacity) into the network (DOE, 2008). We illustrate our methodology with a detailed analysis of an IEEE test case system.

Transmission has long been recognized as a critical component in the reliable supply of electricity. However, as the management paradigm of the system changed, the traditional appraisal of the value of a transmission line may not reflect the contribution of interconnection. Traditionally, the system was operated using dispatchable resources located in far locations, usually close to fuel sources, and shipping this energy to demand centers. Therefore, transmission lines provided a spatial arbitrage function, transferring energy from cheap sources to expensive sinks. As the system has evolved to include more distributed and smaller size resources, the function that a transmission line plays goes beyond the spatial arbitration role. Optimal transmission planning in the presence of policies supporting renewable energy sources (RES) such as renewable portfolio standards (RPS) should take into account the physical and idiosyncratic characteristics of the system (Munoz et al., 2013).

At this point, it is important to question why connecting or improving a connection between two regions is a welfare increasing measure. Eto (2002) found that there are significant savings that can be accrued by improving interconnection links, adding to nearly 13 billion USD per year due to the lower costs of generation. A related question then is what is, if any, the cost of congestion of the transmission system? Table 1 shows estimates of recent congestion costs in two of the deregulated markets in the US. After the Energy Policy Act of 2005 (USCongress, 2005), the US Congress directed the Department of Energy (DOE) to investigate and track the congestion in the interconnected systems (DOE, 2009). Actually, some of the measures enacted after the financial crisis of 2008 envision the strengthening of the bulk transmission system (USCongress, 2008). 
Table 1: Estimated Cost of Congestion

\begin{tabular}{lcr}
\hline & Sales Revenue & Congestion Cost \\
\hline NE & 17 Billion USD ${ }^{a}$ & $125-600$ Million USD \\
PJM & 25 Billion USD & \\
& $\$ 425.2$ Million USD \\
\end{tabular}

But transmission expansion involves the interaction of many components that need to be evaluated, and depending on the topology of the system, in certain cases the strengthening of transmission links can lead to welfare reductions and/or increased congestion. This is an important feature of the flow in transmission systems; the topology of the network and the degree of connectivity amongst buses will affect the externalities observed, and the cost structure of transmission projects leads to lumpiness in the investments made (Joskow and Tirole, 2005).

Our paper fills a gap in the literature by including a nuanced model of the transmission system and the non-linear constraints that are observed in the electricity system for evaluation of transmission assets. Our methodology is the first one to our knowledge to appraise transmission lines according to the value they provide in planning, using a security constrained Alternate Current (AC) Optimal Power Flow (OPF) and taking into account the deliverability of endogenously determined ancillary services. We however do not include integer variables in our evaluation of transmission lines (Munoz et al., 2013).

This paper is organized as follows. Section 2 reviews the relevant literature and presents a model for analyzing the effects of uncertainty in the network. Section 3 discusses the suggested measures of congestion and reliability and outlines our methodology using a stochastic model. Sections 4 and 5 describe the data we utilize and summarize the main results. Section 6 offers concluding remarks.

\section{Theoretical Framework and Related Literature}

The process of transmission expansion in a regulated environment obeys criteria focused on assuring the reliability of the system (Baldick and Kahn, 1993). As deregulation in the generation system advanced, different mechanisms were developed to allow the entry of investors with merchant transmission lines. Nowadays, Regional Transmission Organizations (RTO) and Independent System Operators (ISOs) have different tools to manage congestion using market based mechanisms (e.g., Financial Transmission Rights FTRs Hogan (1992)). One of the challenges faced by the expansion of the transmission system is that the output must be able to both operate in real time, and accommodate the long term changes on generating capacity. Therefore, planners and operators need to provide a cohesive set of incentives for investors in merchant transmission lines to deal with both purposes (Cardell et al. 1997). 
However, market structure and competition can distort the signals in the market (Oren, 1997, Borenstein et al. 2000). Moreover, the existence of market power alters the incentives to support transmission enhancements (Sauma and Oren, 2009); the correction of negative externalities in the presence of congestion can lead to welfare decreasing equilibria (Sauma and Oren, 2007, Downward, 2010); and the uncertainties associated with both political economy issues such as approving and jurisdictional limits, and the inherent difficulty in construction of transmission projects (Schuler, 2012) add to the challenges in transmission planning.

In this context, it is important to take into account that the bulk electricity system has to comply with the reliability criteria set forth by NERC (NERC, 2013). As a matter of fact, the reliability standards point out to the inherent tension in the time scales considered, with Resource Adequacy focusing in long horizons (e.g., Loss of Load Expectation), while operating reliability focuses in short term feasibility (e.g., $n-1$ security).

A further strain source comes from the subsidiarity principle and the interactions between local (e.g., state) and national (e.g., federal) governments: adequacy implies that past investments in the capacity of the electric delivery system must be sufficient to make the real-time operations meet the reliability standards. The responsibility for ensuring that Adequacy standards are met rests with State regulatory authorities. In recent years, and in part exacerbated by the development of wind capacity, the new generation capacity built has focused on the areas with the largest generation potential. These locations are usually far from the main demand centers, which requires the development of inter-state line corridors. Due to the economic and financial implications of maintaining adequacy standards, these developments have implications affecting the total annual cost of delivering real energy to customers that need to be recognized by regulators.

\subsection{Transmission Investment Management}

The use of market based mechanisms to manage congestion has traditionally relied on the use of Locational Marginal Prices (LMP) to indicate the need for expansion on transmission (Lin, 2009). The use of LMPs is closely associated with the idea of transferring electricity from cheap sources to expensive sinks. This concept is applicable when the topology of the network is radial, as is the case with the high tension network for the Western Electricity Coordinating Council. In such case, there are major interconnection corridors, linking the urban centers in California to inexpensive hydroelectric sources in the Pacific Northwest. Other more meshed network topologies may yield more or less accurate results, and this has been a subject of ample debate. The criticisms to this approach come from both the economic and the technical point of view.

The calculation of congestion revenues derived from transferring energy between node A as a source and node B as a sink using the LMPs is defined as follows. 
Definition 1. Denote the Flow on $A B$ as $\left(F_{A B}\right)$

$$
F_{A B}=\frac{(\text { Energy at Node } A-\text { Energy at Node B) }}{2}
$$

The source (Node A) provides positive energy to Line AB and the sink (Node B) withdraws negative energy from Line AB. Energy at each node is measured in units consistent with the clearing process, e.g., MWh. The difference in nodal prices is defined as the nodal price at sink B minus the nodal price at source A.

Definition 2. Define the Congestion Revenue for $A B\left(C_{A B}\right)$ as

$$
C_{A B}=F_{A B} \times(\text { nodal price at Node } B \text { - nodal price at Node } A)
$$

As in the case of Flows, the nodal price at each node is measured in units consistent with the settlement process, e.g., \$/MWh. Therefore, the Congestion Revenue would be measured in dollars (\$). Given these two values, the 'Implied Price' can be defined as follows:

\section{Definition 3.}

$$
\text { Implied Price for } A B=\frac{\text { Congestion Revenue for } A B}{\mid \text { Flow on } A B \mid}
$$

Assuming all flows and congestion revenues were measured in MWh and \$, the implied price would have units of $\$ / \mathrm{MWh}$, similar to the nodal prices. A positive implied price for $\mathrm{AB}$ follows the market logic of flowing energy from cheap sources to expensive sinks. However, negative implied prices are a product of physics laws, violating the market credo.

Congestion occurs in other networked markets, and pricing strategies have been devised to manage this congestion (see Magnanti and Wong (1984) for an example in transportation networks, Henderson et al.(2001) and MacKie-Mason and Varian (1995) for an example in information networks). The main difference with the electricity grid is that the laws of physics known as Kirchhoff's laws govern the way the electricity flows in the system. Even using linear approximations like a direct current power flow (DC PF), the constant balancing between supply and demand necessary for electricity often renders the conclusions from schemes based on latency useless.

Various studies on the economic side have centered around the possibility of exerting market power and the accuracy of the models used (Oren, 1997, Stoft, 1997) under the assumptions established in a plausible model for the transmission network. In this debate, the most salient points are the possibility of oligopolistic practices for certain players with market power. A typical example is the issue of timing of investment (Joskow and Tirole, 2005), where incumbents and early investors can get the benefits from Financial Transmission Rights (FTRs) and engage in a pre-emptive strategy to keep new investors out of the market. This may create network configurations that are not socially optimal, leading to under investment in certain lines (for those owners of congested lines trying to maintain their congestion rents) and over investment in 
other lines (depending on the incentives provided by the regulators). A related literature strand looks at the generation capacity expansion under oligopolistic competition and heterogeneous technologies (Genc and Thille, 2011). However, the timing of transmission and generation investments is usually tiered. Our approach in this paper focuses on the transmission problem, but it can also be used for investment decisions on generation. In fact, the model used in the empirical application determines endogenously the amount of installed generating capacity needed to meet the peak system load and maintain reliability (generation adequacy) for a given network topology.

Besides the economic considerations, there are technical factors: the flows of electricity in an Alternate Current (AC) power network can create situations with non-economic rationale, regardless of the regulatory framework in place (Wu et al. 1996). The failure to account for dynamics and the uncertainty of demand can create stability problems (Yu et al., 1999). Taking into account that the uncertainty in the system is increased by the adoption of RES, we can expect this problem to be heightened in several regions (van der Weijde and Hobbs, 2012).

Further problems exist with the use of LMPs due to the inherent tradeoff between congestion and reliability (Blumsack et al., 2007a). In a meshed network, the addition of a new transmission line can be motivated by reliability concerns (e.g., linking two intermediate buses from generation to load), and yet, create more congestion in the system, in a phenomenon known as Braess's paradox. As noted by Blumsack et al. (2007b), while certain investments are clearly reliability-driven or congestion-driven, the interaction between these two make it more difficult to price the actual benefits and costs of adding a new transmission line, or increasing the capacity of an existing one. Therefore, conventional ways of valuing the transmission lines are inadequate. In a security-constrained framework, this argument takes more relevance in cases when the new lines are part of the set of credible contingencies used by the social planner to optimize the costs in the system.

One of the main difficulties of using LMPs to measure congestion comes from Kirchhoff's Laws, leading to what economists could call 'perverse flows', i.e., shipping energy from expensive sources to cheap sinks.

To illustrate the importance of an electrical network and stochasticity, and the inadequacy of congestion rents, consider the system in Figure 1. In this network, three nodes (buses) are connected by lines of identical capacity $k$. Each bus has a generator $G^{i}$ with a constant marginal cost of fuel $c^{i}$, and a constant demand $d^{i}$. For the sake of simplicity, we ignore the generator limits $\left(P_{\min }^{i}, P_{\max }^{i}\right)$, and assume linearized flow constraints $(\sin \theta \sim \theta)$. We assume the flows $F^{i}$ are clockwise, e.g., $F^{1}$ is the flow from bus 1 to bus 2 . The direction assumed for these flows is arbitrary, but the flow constraints need to be consistent with the direction assumed.

The Ramsey social planner, in this case the system operator, seeks to minimize the cost of meeting demand, subject to the flow constraints. The DC 


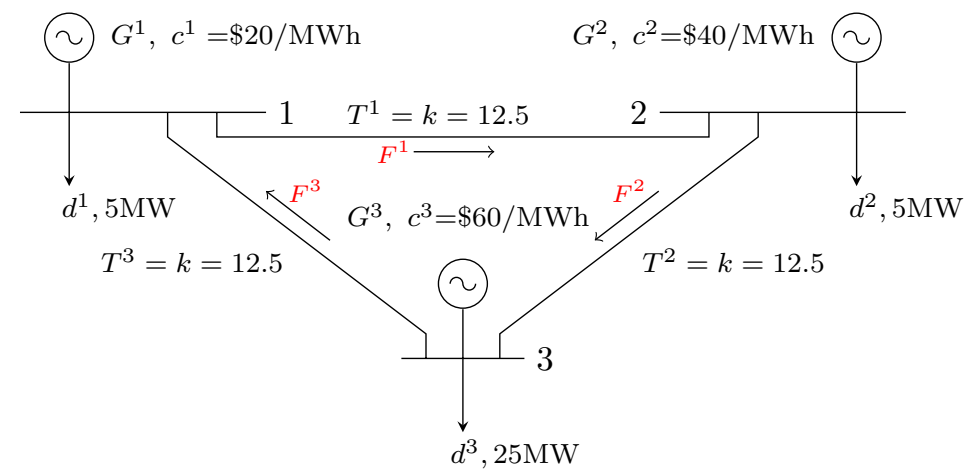

Figure 1: Three Bus Network

Optimal Power Flow (DC-OPF) formulation of this problem is given in (4)

$$
\begin{array}{llll}
\min _{G_{i}} & \sum_{i} c_{i} G_{i} & & \\
\text { st. } & G^{i}-F^{i}+F^{j}=d^{i} & (i, j) \in\{(1,3),(2,1),(3,2)\} & \left(\lambda^{i}\right) \\
& F^{i}-\left(\theta^{j}-\theta^{i}\right)=0 & (i, j) \in\{(1,2),(2,3),(3,1)\} & \left(\lambda_{f}^{i}\right) \\
& -T^{i} \leq F_{i} \leq T^{i} & & \left(\mu_{l}^{i}, \mu_{u}^{i}\right)
\end{array}
$$

The dual variables are shown in parenthesis. The system operator is assumed to have in place a market design that elicits true costs from the rational generators participating. The equilibrium in this case is shown in Table 2

\begin{tabular}{rrrr} 
Table 2: Summary of Optimal Results, Three Bus System \\
\hline & Generation & Price & Flow \\
$i$ & $G^{i^{*}}$, MW & $\lambda^{i^{*}}, \$ /$ MWh & $F^{i^{*}}$, MW \\
\hline 1 & 17.5 & 20.00 & 0 \\
2 & 17.5 & 40.00 & 12.5 \\
3 & 0 & 54.76 & -12.5 \\
\hline
\end{tabular}

The optimal solution uses only the cheapest available generators, 1 and 2 to cover the demand in buses 2 and 3. Two of the lines have binding limits, creating a separation in the prices observed in each bus, with bus 3 having the highest price. There are two notable aspects to this optimal solution: 1) the flow assumed in line 3 is not in the direction assumed (from bus 3 to bus 1 ), but in the opposite direction, as indicated by the negative 12.5 flow. This is consistent with an economic rationale of moving energy from cheap sources (production places) to expensive sinks (consumption places). 2) the flow from bus 1 to bus 2 (line 1 ) is 0 , implying this line is not utilized at all in this case. This is a counterintuitive result. Generator 1, the cheapest generator in the system, is not limited in the amount it can inject into the network (i.e., $P_{\max }^{1}$ 
is not binding); in principle, it could increase its generation from the $17.5 \mathrm{MWh}$ obtained, make use of the spare line 1 capacity, and therefore reduce the cost for the total system. However, Kirchhoff's laws would not allow this increase to occur. This optimal outcome has repercussions in the congestion rent (zero) and implied price for line 1, as it is not well defined in the optimal solution. But more importantly, even though the congestion rent is zero for line 1, it has a very high value for reliability. Assume line 3 (from bus 1 to bus 3 ) has a probability $\pi_{l_{3}}>0$ of being out of service. In this case it is trivially simple to see that line 1 will be necessary to export the cheap generation from Bus 1, and therefore it has a value if the stochastic characteristics of the system are taken into account.

\subsection{Transmission, Reliability and most}

We posit that the evaluation of the transmission reliability, investment and compensation problem should be treated in the framework of stochastic cooptimization (CO-OPT) (Chen et al. 2005$)$. The objective function for the System Operator (SO) minimizes the total expected cost (for active and reactive power, as well as reserves) in a security constrained AC OPF, with a set of credible contingencies. This CO-OPT calculates optimal dispatches, nodal prices and endogenous reserves to be determined simultaneously.

The approach in this paper uses the MATPOWER optimal scheduling tool most framework (Thomas et al., 2008; Lamadrid et al., 2008; Murillo-Sanchez et al. 2013), extending the criteria used in CO-OPT to distinguish between upward and downward reserves for real and reactive power, and takes into account the cost of upward and downward deviations from a "base case" (incs and decs).

The nomenclature for this problem is included in appendix A. The most formulation for the first stage (e.g., period ahead) can be described as follows :

$$
\begin{aligned}
& \min _{\Theta, V, P, Q,} f_{P}(P)+f_{Q}(Q)+f_{R P}\left(R_{P}\right)+f_{R Q}\left(R_{Q}\right) \\
& P^{+}, P^{-}, Q^{+}, Q^{-}, \\
& P_{c}, Q_{c}, R_{P}, R_{Q}
\end{aligned}
$$

With the active power component given by sum of the cost energy, upward and downward deviations from a solved contract:

$$
f_{P}(P)=\sum_{k=0}^{n_{c}} \pi_{k} \sum_{i \in G^{k}}\left[C_{P i}\left(p_{i k}\right)+C_{P i}^{+}\left(p_{i k}^{+}\right)+C_{P i}^{-}\left(p_{i k}^{-}\right)\right]
$$

The reactive component is given by the analogous components, in case reactive costs are included (Thomas et al., 2006).

$$
f_{Q}(Q)=\sum_{k=0}^{n_{c}} \pi_{k} \sum_{i \in G^{k}}\left[C_{Q i}\left(q_{i k}\right)+C_{Q i}^{+}\left(q_{i k}^{+}\right)+C_{Q i}^{-}\left(q_{i k}^{-}\right)\right]
$$


The active reserve cost depends on the maximum deviation upward and downward from a solved contract:

$$
f_{R P}\left(R_{P}\right)=\sum_{i=1}^{n_{g}}\left[C_{R P i}^{+}\left(r_{P i}^{+}\right)+C_{R P i}^{-}\left(r_{P i}^{-}\right)\right]
$$

For generality, reactive reserve costs analogous to the active reserve costs can also be included:

$$
f_{R Q}\left(R_{Q}\right)=\sum_{i=1}^{n_{g}}\left[C_{R Q i}^{+}\left(r_{Q i}^{+}\right)+C_{R Q i}^{-}\left(r_{Q i}^{-}\right)\right]
$$

The non-linear active and reactive power flow equality constraints are described in general form as

$$
\begin{aligned}
& p^{i k}-\sum_{l \in n_{B}}\left|V^{i k}\right|\left|V^{l k}\right|\left[G^{i k, l k} \cos \left(\theta^{i k}-\theta^{l k}\right)+B^{i k, l k} \sin \left(\theta^{i k}-\theta^{l k}\right)\right]=0, \\
& \forall i \in \mathscr{G}, k \in \mathscr{K} \\
& q^{i k}-\sum_{l \in n_{B}}\left|V^{i k}\right|\left|V^{l k}\right|\left[G^{i k, l k} \sin \left(\theta^{i k}-\theta^{l k}\right)-B^{i k, l k} \cos \left(\theta^{i k}-\theta^{l k}\right)\right]=0, \\
& \forall i \in \mathscr{G}, k \in \mathscr{K}
\end{aligned}
$$

All other inequality constraints, including the transmission capacity, generation capability curve, voltage limits, and dispatchable load power factor for all flows are defined in general form by

$$
h^{k}\left(\theta^{k}, V^{k}, P^{k}, Q^{k}\right) \leq 0, \quad k=0 \ldots n_{c} \in \mathscr{K}
$$

There are non-negativity constraints for the post-contingency deviation variables:

$$
\begin{array}{ll}
0 \leq p_{i k}^{+}, & 0 \leq q_{i k}^{+}, \quad \forall i \in \mathscr{G}, k \in \mathscr{K} \\
0 \leq p_{i k}^{-}, & 0 \leq q_{i k}^{-}, \quad \forall i \in \mathscr{G}, k \in \mathscr{K}
\end{array}
$$

The deviation variables (incs and decs) are defined by constraints coupling the base case with the post-contingency flows.

$$
\begin{array}{ll}
p_{i k}-p_{c i} \leq p_{i k}^{+}, & q_{i k}-q_{c i} \leq q_{i k}^{+}, \quad \forall i \in \mathscr{G}, k \in \mathscr{K} \\
p_{c i}-p_{i k} \leq p_{i k}^{-}, & q_{c i}-q_{i k} \leq q_{i k}^{-}, \quad \forall i \in \mathscr{G}, k \in \mathscr{K}
\end{array}
$$

The use of incs and decs in the formulation allows to reflect the operational constraints of different kinds of units with diverse ramping capabilities (Mount et al. , 2010). The reserve variables derived from maximum outputs bound the upward and downwards deviations:

$$
\begin{aligned}
& p_{i k}^{+} \leq r_{P i}^{+} \leq R_{P i}^{P H Y S+}, \quad q_{i k}^{+} \leq r_{Q i}^{+} \leq R_{Q i}^{P H Y S+}, \quad \forall i \in \mathscr{G}, k \in \mathscr{K} \\
& p_{i k}^{-} \leq r_{P i}^{-} \leq R_{P i}^{P H Y S-}, \quad q_{i k}^{-} \leq r_{Q i}^{-} \leq R_{Q i}^{P H Y S-}, \quad \forall i \in \mathscr{G}, k \in \mathscr{K}
\end{aligned}
$$


The deviations from the base case are bounded by the physical ramp rate of each unit:

$$
\begin{aligned}
& -R_{P i}^{P H Y S-} \leq p_{i k}-p_{i 0} \leq R_{P i}^{P H Y S+} \\
& -R_{Q i}^{P H Y S-} \leq q_{i k}-q_{i 0} \leq R_{Q i}^{P H Y S+}
\end{aligned}
$$

In the second stage, the problem of balancing and pricing the real time market is subject to the contracts optimally found in the first stage. Reserve quantities (for active and reactive) have already been determined and procured. For real time adjustments, the formulation is included in Lamadrid and Mount (2012).

The consumer surplus is reflected by including the cost of Load-Not-Served (LNS) as part of the objective function. In cases in which it is economical to shed load, a compensation equal to the Value of Lost Load (VOLL) is given to the demand in the locations (buses) where it is needed. This is an especially important feature in evaluating the requirement of the $n-1$ contingencies, because the compound effect of a high cost with a low probability is consistent with the "one day in ten years" Loss of Load Expectation (LOLE, NERC (2013)) 1 Furthermore, the total weighted system cost is affected according to the impact of the contingency considered. Because reserves are optimally adjusted according to physical and market conditions, this allows to model the addition of stochastic sources of generation to the network. Typically, the amount of reserves needed increases by adding intermittent generation sources. A feature of the most formulation is that spinning reserves for the "base case" $(k=0)$ are contracted and paid ahead of real time operation in, e.g., a day ahead market. The generators are compensated according to the actual energy generated. However, payments can come sequentially, first with the payments from the contracted dispatches, and second, with the offsets between contracted and actual quantities using the real-time prices. It is assumed that each generator is contracted in advance to provide VARs at no additional cost, limited by the specific capability curve. Loads are specified to have constant power factor and consequently nodal prices will cover the cost of both real and reactive power. For the rest of the article, the discussion is centered around real power

\section{Congestion and Reliability in Transmission}

Our focus now turns to the measurement of congestion in a deregulated market. The conventional measure for ex-post congestion is the price differential between two interconnected buses, and a large price difference indicates constraints in the capacity of lines. In deregulated markets, these price differences serve as signals for participants. Besides price signals, technical analyses with

\footnotetext{
${ }^{1}$ Some SO's include hard constraints for their reserve requirements, which can be set by assigning a VOLL of $+\infty$.
} 
information from the operation of the system elucidate the state of the transmission system (ISONE, 2004). Although SOs develop a good understanding of transmission bottlenecks, the measurement of congestion from publicly available data is a relatively new issue(DOE, 2009). Similarly, the design of market mechanisms for dealing with congestion is still in development; PJM has introduced congestion charges that allow market participants to hedge their exposure to congestion (Bowring, 2012). Since the requirement to procure transmission contracts with these congestion charges was eliminated in 2010, this market has seen a significant increase in the volume of transactions, and this is the subject of an on-going debate (PJM, 2012, Brint, 2012).

Our approach to congestion uses the most framework to evaluate the economic value of an individual transmission line by measuring the congestion revenues separately for 1) transferring real and reactive power in high probability, intact system states, and 2) supporting reliability when low probability contingencies occur. We calculate the flows for all system states (intact and contingencies) using equation (1) and derive the congestion revenues using equation (2). Typically, the congestion revenues are positive because energy generally flows from inexpensive sources to expensive sinks. In low probability cases, however, energy may flow from an expensive source to a less expensive sink. For this reason, partitioning congestion revenues this way makes it easier to understand the relative importance of transferring power versus maintaining reliability in determining the role of a transmission line in a network. Congestion revenues are calculated for representative hours in the year and then used to calculate the annual congestion revenues for each transmission line.

The total annual system cost paid by customers consists of the total annual payments for electricity purchases in the wholesale market, plus additional payments to generators and transmission owners to provide the missing money needed to maintain their financial viability (Mount et al., 2012). Generators are paid the nodal prices for energy dispatched in the wholesale market, and generally, this provides some revenue above their out-of-pocket operating costs, but it still may not be sufficient to cover the full cost of capital. Similarly, wholesale payments that are not paid to generators go to transmission owners, but once again, this payment is typically much less than their total capital costs. The marginal economic value of a given transmission line can be calculated by modifying its capacity and comparing the total annual system cost before and after the change. Whenever the network topology is changed, the earnings of both generators and transmission owners are affected (Mount et al. 2009), but there are two main ways of affecting the total annual system cost. These are by changing 1) the total annual operating cost of generation (mainly fuel), and 2) the amount of generating capacity needed to maintain operating reliability and the associated capital costs. Furthermore, we assume that the network topology is fixed unless a specific change to a transmission line is made ex-ante for a particular scenario.

Since the objective of this analysis is to determine the economic value of a transmission line, it is essential to consider the effect of a line on the expected total annual system cost rather than the realized size of the congestion revenue 
because this revenue can change dramatically whenever operating conditions are modified (e.g., in a contingency state). As a result, the observed congestion revenues for a line are generally unreliable measures of value in a meshed network $2^{2}$ For this reason, we propose evaluating changes in the three following criteria to measure the value of a change in the capacity of a transmission line.

1. The real system cost of operation. This is primarily the fuel costs and it also includes compensation for ancillary services (e.g., providing reserve capacity)

2. The cost to customers of any load not served

3. The capital cost of generating capacity and transmission. This typically includes net revenue above operating costs in the wholesale market as well as the additional compensation necessary to make generators and transmission owners financially adequate (i.e., compensation for "missing money") ${ }^{3}$

A flow diagram summarizing our proposed methodology using most is shown in Figure 2. The stochastic inputs (I) include variable sources of generation (e.g., renewables), and variability in the costs for generators and equipment failure (e.g., natural gas prices and contingencies respectively). The network and system topology $(\mathrm{N})$ encompasses all system information and includes the $\mathrm{AC}$ parameters for the network (e.g., lines' susceptance, reactive demands and supplies) and the operating capabilities of generating units. Both the stochastic inputs (I) and the network and system topology are user provided, and represent the most up to date available information for evaluation. A component that provides robustness in the operation of the system is an analysis of possible contingencies in operation. This contingency analysis is usually performed offline Choi et al. (2007). The most model (M) is described in Murillo-Sanchez et al. (2013) and Section 2.2. The parameters of the policy evaluated (P) include changes in transmission capacity and in the compensation scheme for paying renewable generation. The calculation of the optimum nodal prices (S) and expected congestion revenues over the stochastic inputs serves as a screening mechanism for identifying individual lines that have the largest impact on the system. The evaluation of the policy $(\mathrm{C})$ uses the three criteria proposed above and the expected total system cost. This process is performed for all the candidate policies to be evaluated. We illustrate each element in the following sections.

\footnotetext{
${ }^{2}$ In special circumstances when, for example, the network is radial rather than meshed, the congestion revenues for major tie-lines are more accurate measures of value.

${ }^{3}$ Some analyses consider that lower wholesale prices are an indication of a positive system benefit, but this may not be true because it ignores payments made outside the wholesale market.
} 


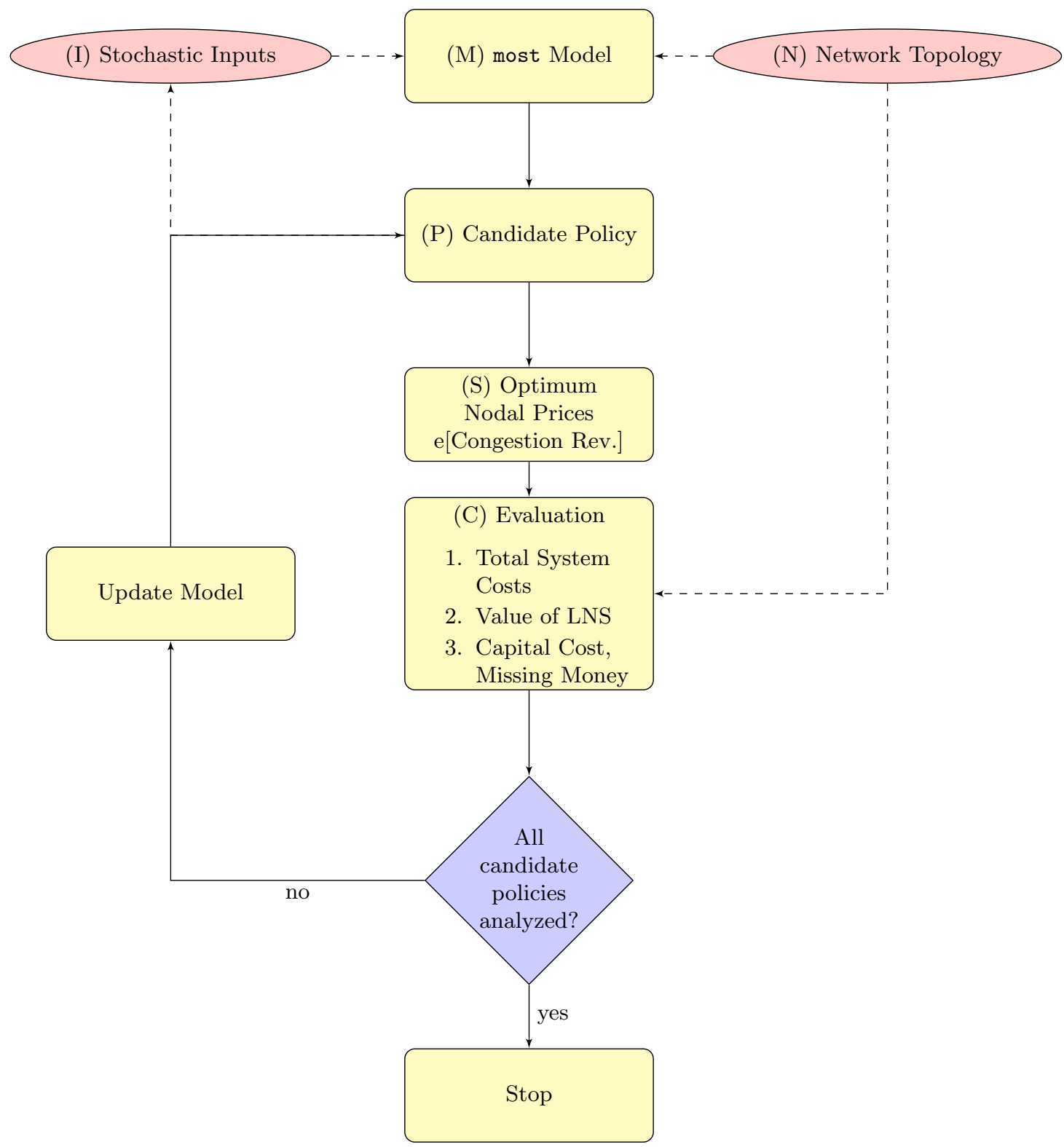

Figure 2: Suggested Methodology for Evaluating Transmission Changes

\section{Input Specifications for the Analysis}

To demonstrate how the analytical framework described in the previous section can be used to evaluate different measures of the value of individual transmission lines, most is applied to a test network using MATPOWER. The analysis 
evaluates the effects on system costs of adding new wind capacity that replaces some installed coal capacity, and the effects of changing the capacity of selected transmission lines. The objective of this section is to describe how the inputs are derived for the analysis that is presented in Section 5

\subsection{The Network Model}

The case studies use a modified version of the IEEE 30-bus system Alsac and Stott, 1974, Ferrero et al., 1997). This test network is divided into three regions. Area 1 represents an urban center with expensive sources of generation, a high load and a high VOLL (\$10,000/MWh) (Joskow, 2012). Areas 2 and 3 represent rural areas, with relatively inexpensive generation, relatively small loads, and lower VOLLs $(\$ 5,000 / \mathrm{MWh})$. Given this setup, an economically efficient dispatch would use as much of the inexpensive generation in Areas 2 and 3 as possible to meet the load in Area 1.

The one-line diagram of this network is shown in Figure 3.

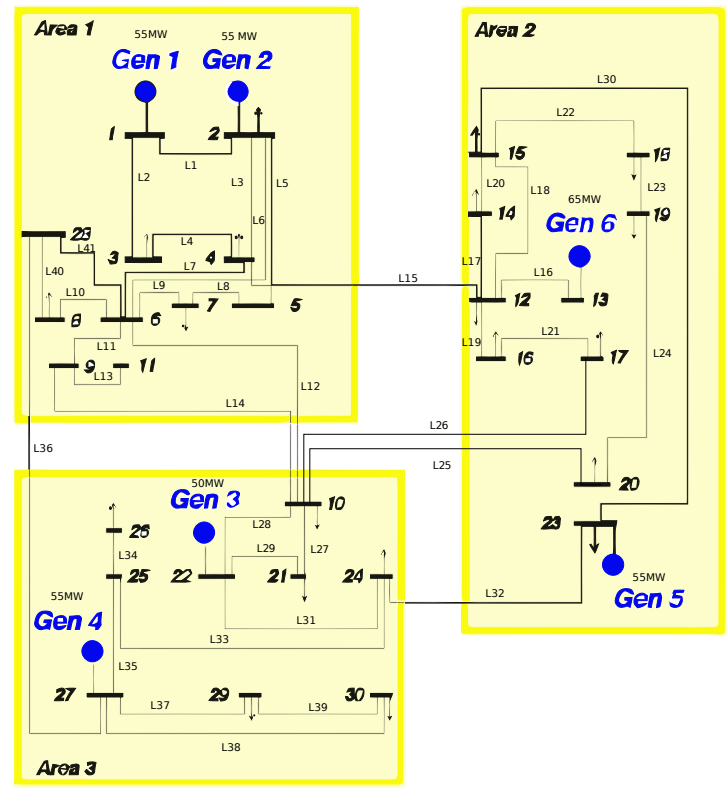

Figure 3: A One-Line-Diagram of the 30-Bus Test Network.

The thermal capacities of the tie-lines linking the rural areas with the urban center are modified to replicate the congestion observed in the Eastern Interconnection, especially in the transmission corridors supplying Philadelphia and New York City, as illustrated in Figure 4

The test network has 12 generators with specified capacities and fuel types. The fuels considered are Nuclear, Hydroelectric and refuse (NHR), Coal, Combined Cycle Gas Turbines (CC Gas), Combustion Gas Turbines (CGT) and 


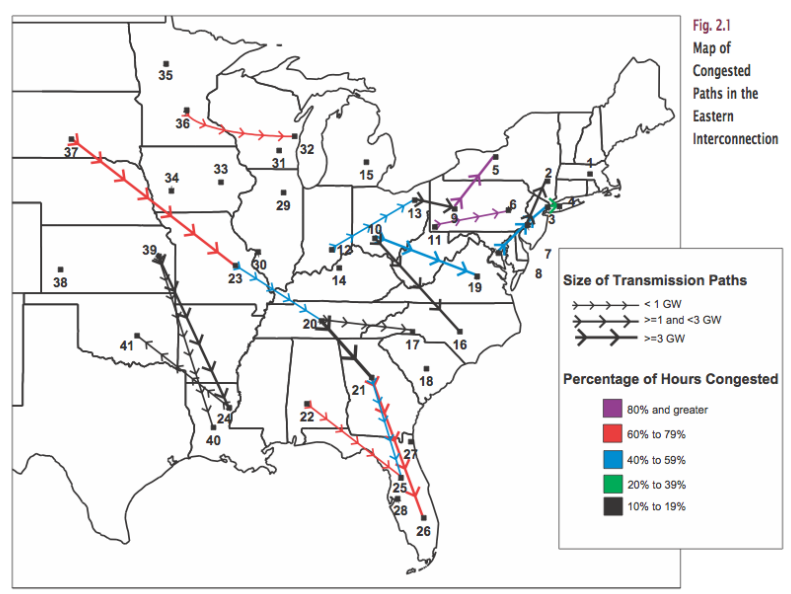

Figure 4: Congested Paths in the Eastern Interconnection, Eto 2002)

Fuel Oil Generators. The capacity proportions for each fuel type reflect the actual composition for the US portion of the North Eastern Power Coordinating Council (Allen et al., 2008). Table 3 summarizes the fuel capacities and costs per area.

\subsection{Demand Modeling}

The demand is modeled using an annual load duration curve (Vardi et al. 1977) and it identifies loads in urban centers and loads in rural areas separately. The two load profiles are used to scale load in Area 1 and loads in Areas 2 and 3 for the analysis. The ranked hourly loads for the 8760 hours of the year are grouped into 100 bins, with 87 hours in each bin. The total load for the 30 bus test network is 223MW at the peak, with 84.3 MW in Area 1, 56.2 MW in Area 2 and $48.5 \mathrm{MW}$ in Area 3. At the lowest demand level, the total system load is 103MW. Comparing these loads to the generation capacity in each area (Table 3), there is more than enough capacity to meet system adequacy requirements. Each one of the demand bins is associated with different forecasts of potential wind generation, and in general, the forecasts of wind generation are negatively correlated with the demand.

\subsection{Wind Modeling}

The characterization of wind follows the description in Anderson and Cardell (2008), with three main building blocks. The first block is a set of historical time-series data for wind speeds (this study uses hourly New England data). The second block is an ARMA model for predicting wind speed, in this case, one hour ahead forecasting. The third block is a power curve for a wind turbine, relating wind speed to potential wind generation.

For each load bin, the ARMA model provides three different forecasts of wind speed (High, Medium and Low) with different probabilities of occurring, 
Table 3: Summary of Generation Capacity and Demand, 30 Bus system

\begin{tabular}{lrrrrrrrr}
\hline & \multicolumn{7}{c}{ Generation Type } & \\
\cline { 2 - 7 } Area & Wind & Coal & CC Gas & CGT & Oil & NHR & TAreaG & Demand \\
\hline 1 & 0 & 0 & 0 & 45 & 65 & 0 & 110 & 84 \\
2 & 0 & 70 & 0 & 0 & 0 & 50 & 120 & 56 \\
3 & $0-105$ & 0 & 40 & 0 & 0 & 65 & 105 & 49 \\
\hline TCap. & $0-105$ & 70 & 40 & 45 & 65 & 115 & 335 & 189 \\
PCost & $-1,500-0$ & 25 & 55 & 80 & 95 & 5 & & \\
\hline
\end{tabular}

derived from the historical data. In addition, each forecast has four realized wind speeds, with different probabilities of occurring, that are transformed to potential wind generation 4 For a given load bin, most determines an optimum pattern of dispatch for each one of the three forecasts separately, treating the realized wind speeds as four different system states. In other words, it is assumed implicitly that an SO gets either a High, Medium or Low forecast, and for a given forecast, the different realizations represent the stochastic nature of this input. In addition, there is uncertainty about which one of the three forecasts will occur.

Table 4 summarizes the forecasts and realizations with their associated probabilities. Each one of the three forecasts represents a non-overlapping range of wind speeds, but the range of the corresponding realized wind speeds is much larger because it is derived from the stochastic properties of the estimated ARMA model. Using the power curve to transform wind speed leads to a wide range of potential wind generation. For example, for a Low wind forecast, realizations are low most of the time (66\%), but there is a small probability $(3 \%)$ that the turbines will generate at $73 \%$ of the maximum capacity. The Medium forecast is more evenly distributed, but the High wind forecast is especially challenging. Although the turbines can generate at maximum capacity most of the time $(70 \%)$, there is a substantial probability $(14 \%)$ that the turbines will cutout to avoid damage when the wind speed is above $25 \mathrm{~m} / \mathrm{sec}$.

The previous discussion describes the stochastic characteristics of "Normal wind". In addition, there are two modifications of Normal wind that represent a less uncertain source, Nice wind, and a more uncertain source, Nasty wind. The rationale for specifying these three types of wind generation in table 4 follows:

1. Normal wind: The potential levels of wind generation correspond to historic data and the marginal operating cost is $0 \$ / \mathrm{MWh}$.

2. Nice wind: This source corresponds to the effect of coupling Normal wind with some form of storage capacity $5^{5}$ and the marginal operating cost is

\footnotetext{
${ }^{4}$ Some of the potential wind generation may be spilled in the optimum dispatch.

${ }^{5}$ The storage is charged when the wind speed is high and discharged when wind speed is low, and importantly, when wind speed is very high and generation is curtailed to protect the
} 
also $0 \$ / \mathrm{MWh}$.

3. Nasty wind: This source is the same as Normal wind but all potential wind generation is dispatched, and this corresponds to a "Must Take" contract between the wind generator and the system operator (in the analysis, the marginal operating cost is set to $-1,500 \$ / \mathrm{MWh}$ to make spilling wind generation unacceptably expensive).

The wind farm is located at bus 13 , a node connected also to a coal and a nuclear generator with capacities of 35 and $30 \mathrm{MW}$ respectively. The coal capacity at bus 6 is reduced in four consecutive steps by one third of the wind capacity added. Each increment increases wind capacity at bus 13 by $26.25 \mathrm{MW}$ and reduces coal capacity at bus 6 by $8.75 \mathrm{MW}$ simultaneously. These assumptions approximate the current procedures adopted by regulators of derating the nameplate capacity of installed wind turbines to reflect their actual capacity factors derived, for example, from simulated data in the Eastern Wind Interconnection and Transmission Study (EWITS) (NREL, 2010).

Table 5 summarizes the tradeoff between the coal and the wind generator placed in bus 13 .

\subsection{Contingencies in the system}

We include a number of low probability contingency states that represent unplanned equipment failures (outages). The set of credible contingencies considered includes line outages in the urban area, line outages between the urban

turbines.

Table 4: Specifications of the Wind Contingencies

\begin{tabular}{|c|c|c|c|c|}
\hline \multirow{2}{*}{$\begin{array}{c}\text { Forecasted } \\
\text { Wind Speed }\end{array}$} & \multirow{2}{*}{$\begin{array}{l}\text { Probability } \\
\text { of Forecast }\end{array}$} & \multicolumn{2}{|c|}{ Wind Generation $^{a}$} & \multirow{2}{*}{$\begin{array}{c}\text { Output } \\
\text { Probability }^{b}\end{array}$} \\
\hline & & Normal & Nice & \\
\hline \multirow{4}{*}{$\begin{array}{c}\mathrm{LOW} \\
(0-5 \mathrm{~m} / \mathrm{s})\end{array}$} & \multirow[t]{4}{*}{11} & 0 & 33 & 66 \\
\hline & & 7 & 33 & 26 \\
\hline & & 33 & 33 & 5 \\
\hline & & 73 & 38 & 3 \\
\hline \multirow{4}{*}{$\begin{array}{l}\text { MEDIUM } \\
(5-13 \mathrm{~m} / \mathrm{s})\end{array}$} & \multirow[t]{4}{*}{46} & 6 & 41 & 24 \\
\hline & & 38 & 55 & 20 \\
\hline & & 62 & 55 & 18 \\
\hline & & 93 & 58 & 38 \\
\hline \multirow{4}{*}{$\begin{array}{c}\text { HIGH } \\
(13+\mathrm{m} / \mathrm{s})\end{array}$} & \multirow[t]{4}{*}{43} & 0 & 35 & 14 \\
\hline & & 66 & 70 & 4 \\
\hline & & 94 & 70 & 3 \\
\hline & & 100 & 70 & 79 \\
\hline
\end{tabular}

$a \%$ of Installed Wind Capacity, $105 \mathrm{MW}$ of Wind capacity installed.

${ }^{b}$ Conditional on Forecast. 
Table 5: Wind and Coal Tradeoff

\begin{tabular}{lrr}
\hline & $\begin{array}{r}\text { New Wind } \\
\text { Cap. (MW) }\end{array}$ & $\begin{array}{r}\text { Coal Unit } \\
\text { Cap. (MW) }\end{array}$ \\
\hline No wind ("0") & 0 & 35 \\
1st wind penetration level ("1") & 26 & 26 \\
2nd wind penetration level ("2") & 53 & 18 \\
3rd wind penetration level ("3") & 79 & 9 \\
4th wind penetration level ("4") & 105 & 0 \\
\hline
\end{tabular}

and the rural areas, full outage of generation at a given bus. The individual probabilities of failure are very small ( $0.2 \%$ for each failure), and given the fifteen contingencies considered in the analysis, the system is expected to be intact 97 percent of the time. The different levels of potential wind generation shown in table 4 are allocated over this intact system. In this setup, the amount of reserve capacity needed to maintain Operational Reliability is expected to increase with higher wind penetrations 6

\section{Synthesis and Results}

The analysis in this section presents an evaluation of the results for the three types of wind generation shown in table 4 , the different levels of installed capacity shown in table 5 including cases with no wind capacity, and three different network topologies. It focuses on the realized congestion revenues for individual transmission lines and the expected total annual system costs. For Normal wind, the potential levels of generation shown in table 4 . Normal wind Column are used, with $0 \$ / \mathrm{MWh}$ marginal cost. In the case of Nice wind, the potential levels of generation shown in table 4 . Nice wind Column are used, with $0 \$ / \mathrm{MWh}$ marginal Cost. The levels shown represent the effect of coupling an energy storage system (ESS) to the wind farm, therefore reducing the range of outcomes. For Nasty wind, the potential levels of generation shown in table 4 Normal wind Column are used, with $-1,500 \$ / \mathrm{MWh}$ marginal cost. The negative marginal price is equivalent to a must-take requirement for the system operator, given the minimization of costs of the objective function. The different network topologies correspond to 1) the initial system, 2) an upgrade in the capacity of a tie-line linking Area 2 (where the wind farm is located) to Area 1 (the major load center), and 3) a downgrade of a transmission line that is crucial for maintaining reliability when contingencies occur. Table 6 summarizes the cases considered and the No wind cases $(1,1 \mathrm{u}$ and $1 \mathrm{~d})$ are treated as the base cases. The first part of the analysis shows that the Implied Prices for individual transmission lines, defined in Eq. (3), are very sensitive to the state of the

\footnotetext{
${ }^{6}$ This phenomenon has already been observed in Europe, with operating reserves increased by almost 10\% in some countries (Spiecker and Weber 2011, Troy et al. 2012).
} 
network, and they are highly volatile in different system states. Furthermore, it is only in unusual circumstances that the expected congestion revenues of individual lines are reliable measures of their economic value. The remainder of the analysis focuses on a better way of measuring these economic values using the expected total annual system costs for a given case. Changes in this total cost provide a valid way to evaluate the effects of changing the network topology and increasing the amount on wind generation.

\begin{tabular}{llcc}
\multicolumn{4}{c}{ Table 6: Cases Simulated } \\
\cline { 2 - 4 } Case & Wind & Upgrade L15 $(+100 \%)$ & Downgrade L22 (-25\%) \\
\hline 1 & \multicolumn{3}{c}{ Yes changes } \\
$1 \mathrm{u}$ & \multicolumn{3}{c}{ Yes } \\
$1 \mathrm{~d}$ & & & \\
2 & Normal & & Yes \\
$2 \mathrm{u}$ & Normal & Yes & \\
$2 \mathrm{~d}$ & Normal & & Yes \\
3 & Nice & & \\
$3 \mathrm{u}$ & Nice & Yes & \\
$3 \mathrm{~d}$ & Nice & & Yes \\
4 & Nasty & & \\
$4 \mathrm{u}$ & Nasty & Yes & \\
$4 \mathrm{~d}$ & Nasty & & \\
\hline
\end{tabular}

Figure 5 shows the hourly Implied Prices for Case 2 with Normal wind for all transmission lines in all system states over an annual simulation. The horizontal axis corresponds to the individual transmission lines in the system (41 transmission lines). The vertical axis measures the implied prices. Since there are 100 load bins, and for each one, there are four intact states (for the wind realizations) and 15 contingencies, each transmission line has $100 \times 4 \times 3=$ 1,200 Implied Prices for the intact states (solid red circles) and $100 \times 15 \times 3=$ 4, 500 Implied Prices for the contingency states (dotted blue crosses). The implied prices range from $-\$ 2,500 / \mathrm{MWh}$ to $+\$ 5,000 / \mathrm{MWh}$ even though there is no speculation by generators 7 This is a very large range considering that typical nodal prices range between $\$ 0 / \mathrm{MWh}$ and $\$ 100 / \mathrm{MWh}$, and it is caused, to a large extent, by shedding load at a high VOLL in some contingency states. In fact, there are major differences in the implied prices between intact states and contingency states. For the intact cases, the range of Implied Prices is relatively small and they appear as a single observation in Figure 5 . In contrast, for the contingency states, there are a number of states with negative prices (e.g., Line 25 ), and others with very high prices, particularly for line 22. In a contingency

${ }^{7}$ The highest offer submitted into the wholesale market is less than $\$ 100 / \mathrm{MWh}$ 


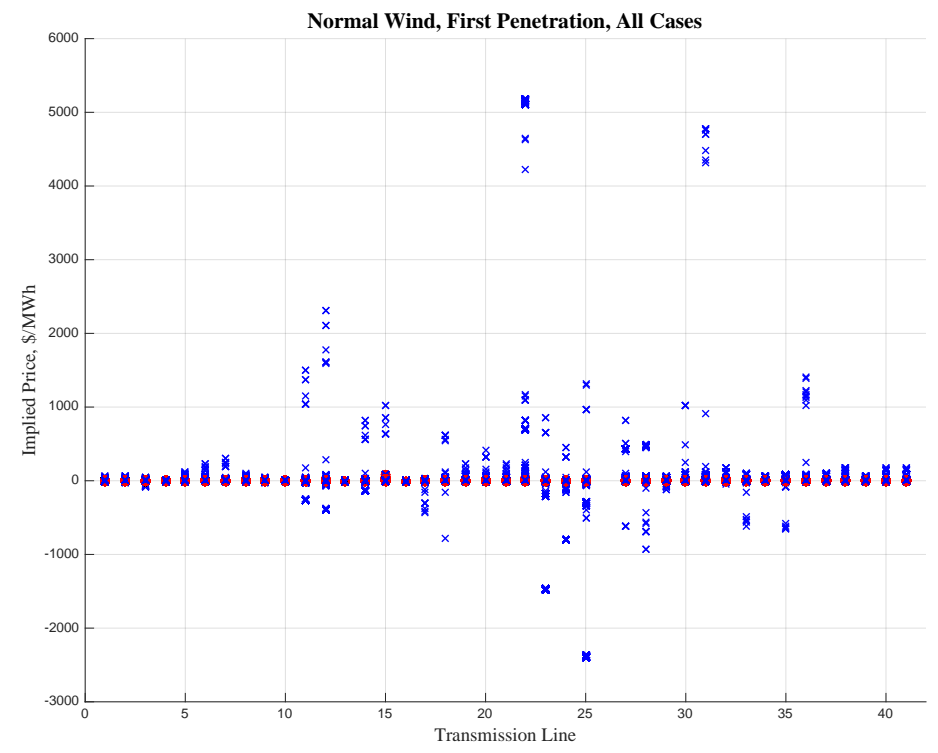

Figure 5: Implied Nodal Prices for Individual Transmission Lines.

state, even though the probability of it occurring is very small $(0.2 \%)$, the effect on the expected Implied Price can still be substantial (e.g., $0.002 \times 15,000=$ $\$ 30 / \mathrm{MWh})^{8}$

To focus on the price differences for intact states only, the corresponding Implied prices for Case 2 with Normal wind are taken from Figure 5 and shown in Figure 6. In this reduced set, the prices for individual transmission lines range from $-20 \$ / \mathrm{MWh}$ to $\$ 80 / \mathrm{MWh}$. The largest negative prices occur on line 18 in area 2 (rural), and the highest positive prices occur in the tie-line linking area 2 (rural) to area 1 (urban center). The other tie-lines to the urban center (lines 12, 14 and 36) have generally positive Implied prices, but with lower magnitudes than line 15. Contrasting with this result, the tie-lines between the rural areas (areas 2 and 3 ) have some positive prices (line 32) and some negative prices (line 25). The main conclusion is, however, that the Implied prices for individual lines can still vary in a wide range even for the intact states.

\subsection{Annual Expected Congestion Revenues}

The main purpose of this section is to aggregate the congestion revenues over all system states and all 100 load levels to compute the expected annual conges-

\footnotetext{
${ }^{8}$ Although this specified value of VOLL may appear to be unrealistically high, the published value of $\$ 36,762 / \mathrm{MWh}$ (Lawton et al. 2003) is even higher, which puts our value on the conservative side.
} 


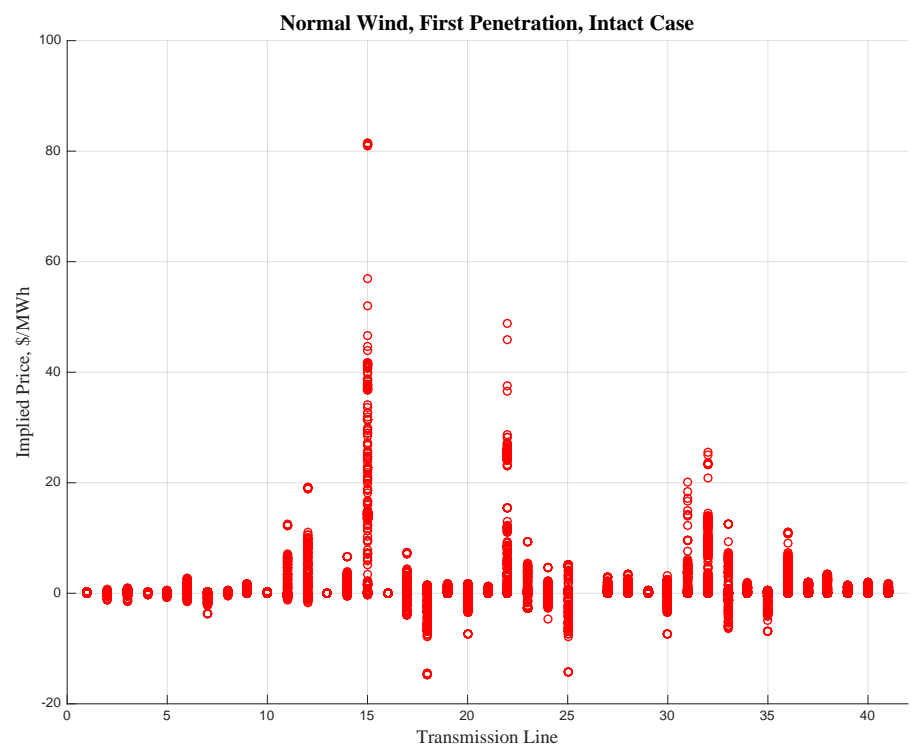

Figure 6: Implied Nodal Prices for Individual Transmission Lines

tion revenue for each transmission line. For explanatory purposes, congestion revenues are determined separately for 1) intact states, the income from price arbitrage (i.e., transferring power from cheap sources to expensive sinks), and 2) contingency states, the income for maintaining reliability. Since the annual totals are weighted by probabilities, the revenues from the intact states have larger weights than the revenues from the contingency states. The expected annual congestion revenues for both the intact and contingency states are presented in Figure 7 for all lines using Case 2 with Normal wind.

The results have two important implications for regulators. First, the main source of congestion revenue is different for different lines. For example, most of the revenue for line 15 (the tie-line that links the wind farm to the urban center) comes from the intact states, while most of the revenues for lines 22 and 32 come from the contingency states. Second, the magnitudes of the revenues differ sharply, with some lines earning close to zero (e.g., lines 1, 2, 10), and some lines loosing money (e.g., lines 23, 25 and 30). The largest revenues are for Line 15, mainly for transferring power, and for Lines 22 and 32, mainly for maintaining reliability. The main conclusion is that for some lines the main source of congestion revenue comes from contingency states. When evaluating the value of an individual line, it is not enough to simply measure the congestion revenues for transferring power when the system is intact. 


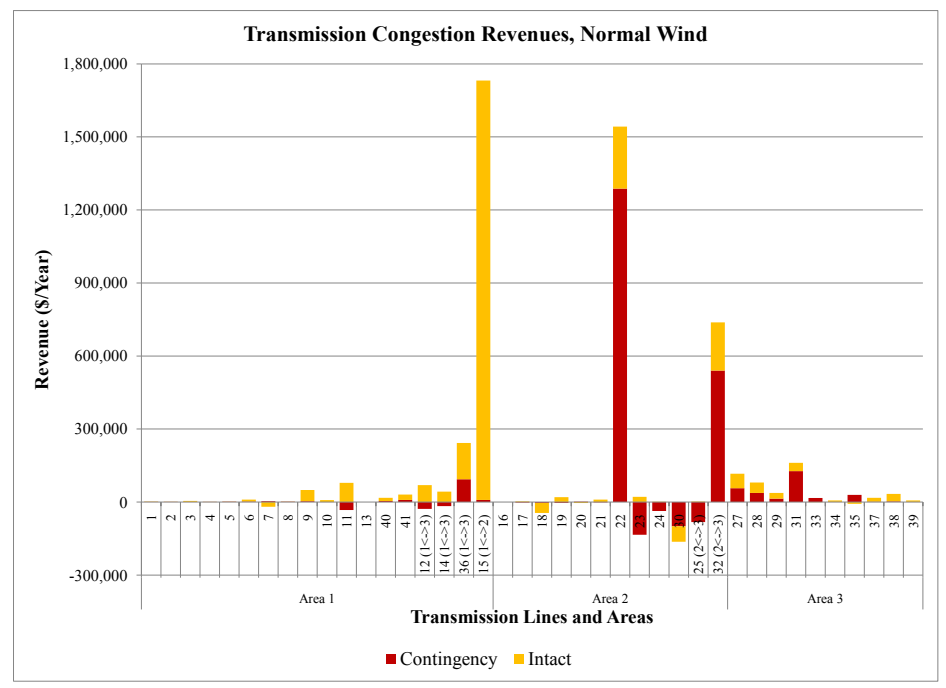

Figure 7: Expected Annual Congestion Revenues (first wind penetration).

\subsection{Reliability, Robustness and Economic Value}

This section introduces a better way to determine the economic value of an individual transmission line using the total annual cost of a network that includes both operating costs and capital costs. Based on the magnitudes of the annual congestion revenues for individual lines identified in Section 5.1 and shown in Figure 7, the following two lines stand out: 1) Line 15 for transferring power and 2) Line 22 for maintaining reliability. To illustrate the effect of changing the network topology, the analysis considers the economic effects of upgrading a single transmission line and downgrading a single transmission line (lines 15 and 22 respectively). In addition, these changes are evaluated for the different penetration levels of wind capacity and the different types of wind quality shown in table 4. The analysis assumes that the wholesale market is deregulated and that all transactions are settled using Locational Marginal Prices (LMPs).

The total annual cost includes all operating costs and the annualized capital costs of conventional generating capacity and transmission ${ }^{9}$ It is composed of 1 )

\footnotetext{
${ }^{9}$ The operating cost of the wind turbines is specified to be zero, and the corresponding capital cost is not included because the amount of installed wind capacity is treated as a policy scenario. The amount of generating capacity needed to maintain system reliability (adequacy) is determined endogenously by most, and it changes when the amount of wind capacity or the quality of wind generation changes.
} 
the operating costs, mainly for fuel and reserve capacity, 2) the net earnings for conventional generators above their operating costs, 3 ) the net earnings for wind generators, 4) the Missing Money (MM) for generators ${ }^{10} 5$ ) the net earnings collected by the system operator that is paid to transmission owners, 6) the MM for transmission owners, and 7) the cost of load-not-served to customers.

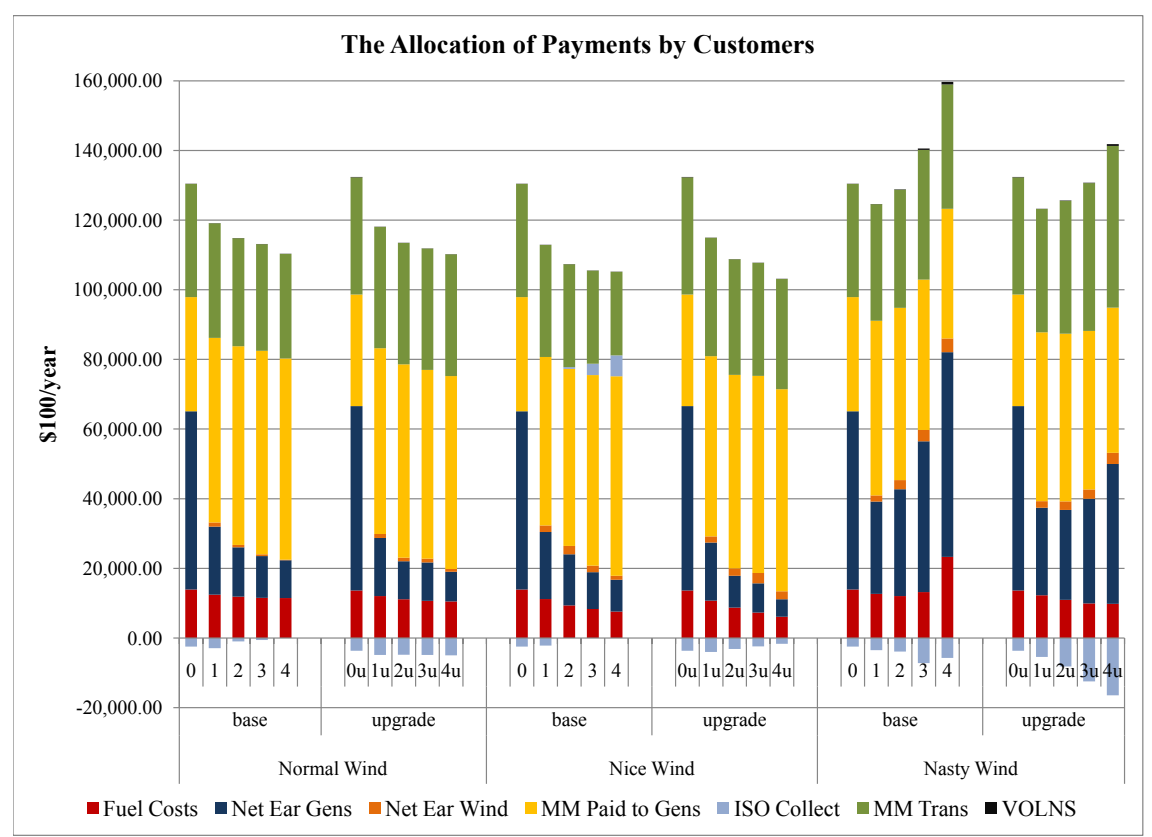

Figure 8: Composition of Customer Payments, Line 15 Upgrade

Figure 8 shows the expected total annual costs (payments by customers) for the initial network and a network with increased transfer capacity from doubling the capacity of line 15. For Normal and Nice wind, increasing the wind capacity reduces the total cost because adding wind capacity displaces more conventional generation and lowers the operating costs, particularly when the tie-line is upgraded. In addition, the wholesale prices are reduced but this effect is partially offset by higher payments for missing money. The main difference between Normal and Nice wind is that less wind generation is spilled with Nice wind at the higher levels of wind capacity. In contrast, for Nasty wind the effects are

\footnotetext{
${ }^{10}$ This is the additional revenue needed above their net earnings to cover the full capital cost. A more detailed explanation of missing money can be found in Mount et al. (2012)
} 
fundamentally different, and increasing the wind capacity above the first level increases the total annual cost substantially. Even though more wind generation is dispatched, it is costly for the network to accommodate this additional power because expensive conventional generating units must be dispatched to balance the flows on the network and obey Kirchhoff's laws. Wholesale prices increase and this leads to higher net earnings for generators and transmission owners (Lamadrid et al., 2014). As a result, payments for missing money are lower. However, the most important difference is that upgrading line 15 reduces the total annual cost a lot more than it does with Normal and Nice wind because this upgrade reduces much of the stress on the network associated with Nasty wind.

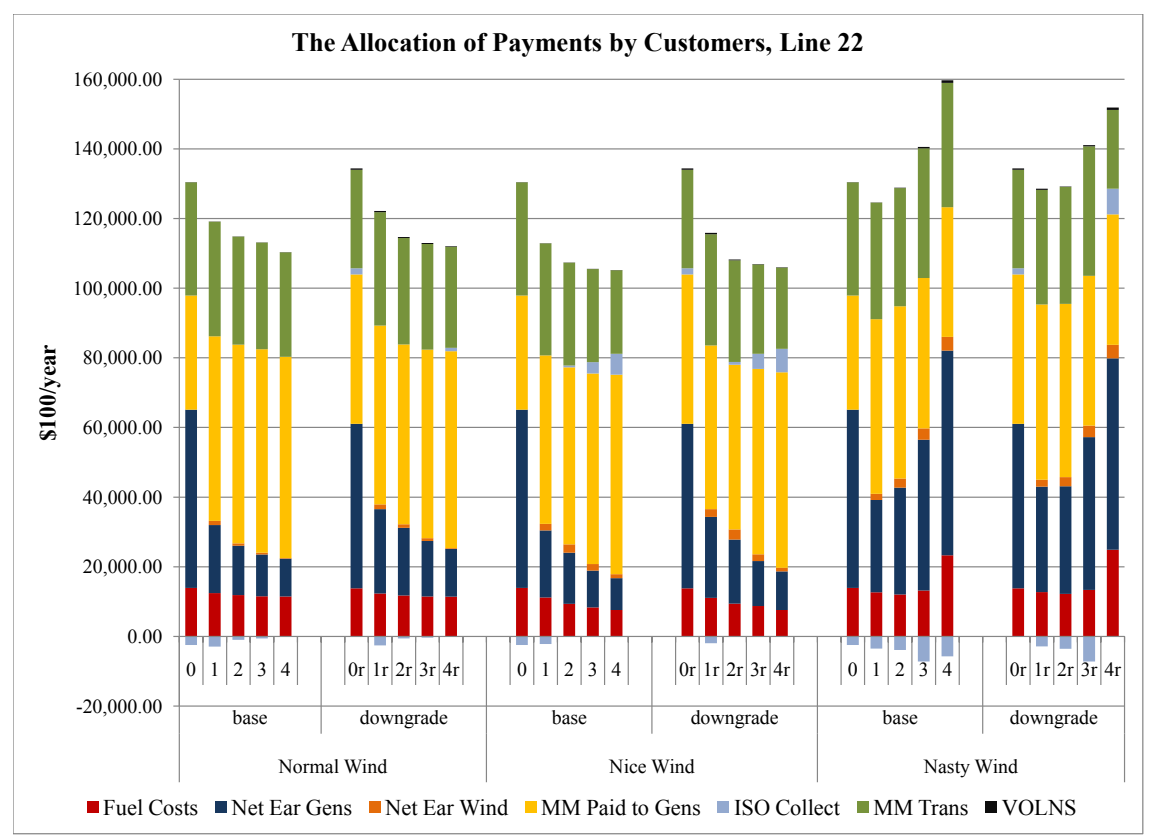

Figure 9: Composition of Customer Payments, Line 22 Downgrade

The effects of reducing the reliability of the network by downgrading line 22 to $75 \%$ of its original capacity are shown in Figure 9. The results for the base network are identical to those shown in Figure 8. Overall, downgrading line 22 generally results in increases in the total system costs but these magnitudes are relatively small compared to the effects of upgrading line 15 .

The effects of upgrading Line 15 and downgrading Line 22 on the total annual cost are shown in Figure 10 for the different penetration levels of wind 
capacity and the different types of wind quality. Given that both Lines 15 and 22 earn large positive congestion revenues (see Figure 7), one would expect that, in general, an upgrade of Line 15 would reduce the total annual cost, and conversely, downgrading Line 22 would increase the total annual cost. The results are however more complicated and differ markedly according to the type of wind quality.

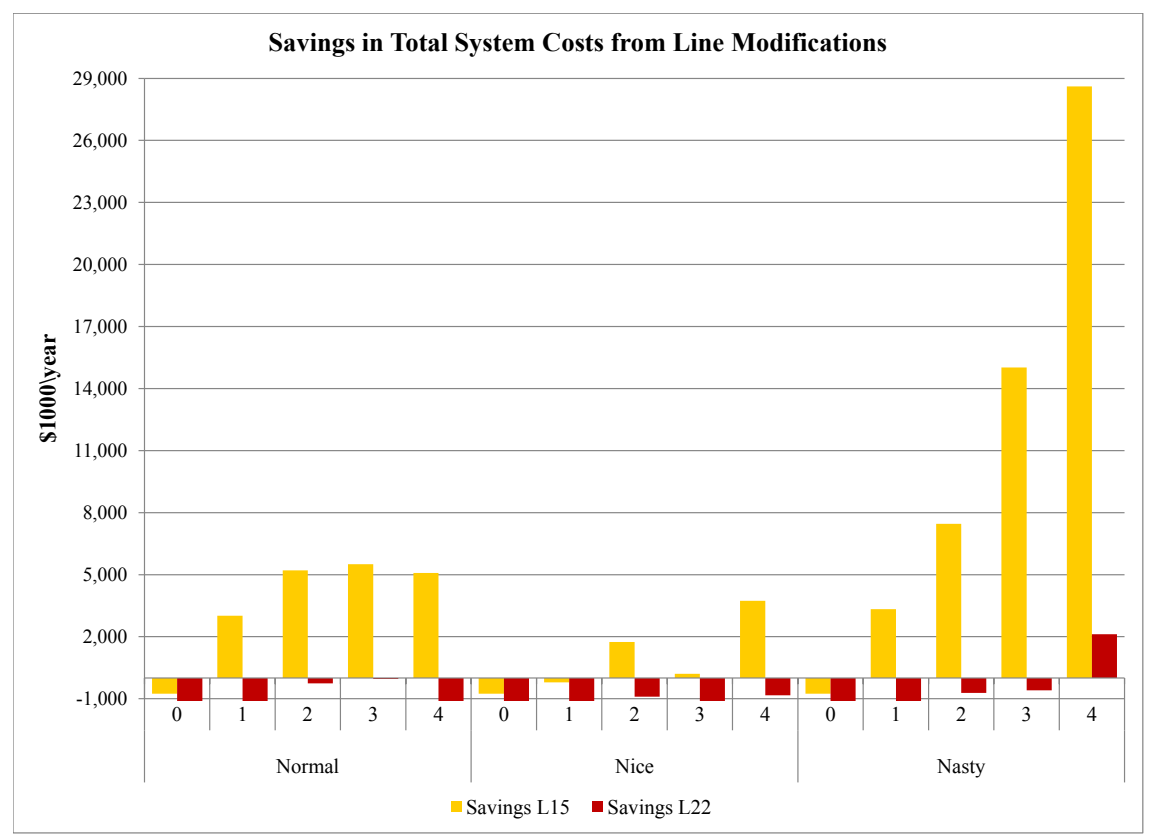

Figure 10: Annual Savings from Transmission Upgrade

The results closest to prior expectations are exhibited by Nasty wind when line 15 is upgraded. Due to the location of the wind farm, and given the musttake contracts for wind generation, the benefits of upgrading line 15 increase when the level of wind penetration increases. The positive savings for Normal wind are consistent with expectations and increase with the level of wind penetration for all levels except the highest one. However, the magnitudes of the savings are relatively modest compared to the Nasty wind case. The most surprising result is for Nice wind because the savings are both positive and negative and there is no consistency with the level of wind penetration. The implication of Nice wind is that coupling storage with wind generation is an effective way to substitute for upgrading line 15.

The savings from downgrading line 22 (reliability edge) are small and gen- 
erally negative as expected. However, there is no consistency between these magnitudes and the levels of wind penetration. The effects are idiosyncratic to the specific network studied and the assumptions made in the study. There is one apparent anomaly and this is the positive savings for Nasty wind at the highest level of wind penetration. The main reason for this unusual result is that the net earnings collected by the system operator are negative with the base network and positive when Line 22 is downgraded.

\subsection{Discussion}

The SCOPF (most) used for this analysis determines both the optimum dispatch and the optimum amount of reserve generating capacity by minimizing the expected cost of meeting load over an explicit set of credible contingencies. The obtained nodal prices reflect the patterns of dispatch for the intact and for the system with contingencies. The crucial difference between this model and a standard AC OPF stems from the possibility of shedding load at very high costs, i.e., turning a constraint into a component of the objective function. The reserves necessary for operational reliability are determined endogenously, and in a long term planning model as the one used in this article they indicate the requirements from the generation side. These reserves are a continuous variable. We are currently working on including integer variables in order to reflect the discretionary nature of the generation investments. A further extension of this work is the formulation of a dynamic model that takes into account the transitions over time, accounting for the hysteresis effects in investments. We are currently implementing a multi-period model to study this. One of the main difficulties of this model is the computational complexity. For this reason, we are exploring equivalent formulations using Second Order Cone Constraints (Lobo et al., 1998) and Benders decomposition (Benders, 1962).

\section{Conclusions}

Even though many regulators believe that the size of the congestion rents on a transmission line provides a reliable criterion for deciding whether to invest in an upgrade, this rationale is predicated on the assumption that the role of transmission is to transfer energy from inexpensive sources to expensive sinks. The results in this paper demonstrate that this is generally not true for a meshed network when there is uncertainty in system conditions due, for example, to the stochastic nature of wind generation and unexpected equipment failures (contingencies). Transmission lines also help to maintain the Operating Reliability of a network, and changing the level of uncertainty on a network has major effects on the economic value of individual transmission lines.

Maintaining the reliability of a meshed network is achieved by having transmission lines that provide enough redundant capacity to withstand unpredictable changes in operating states. Since the support of reliability is essentially a public good, merchant transmission owners will tend to under-invest in the transmission lines needed for reliability purposes. In practice, however, many transmis- 
sion upgrades are justified on the basis of reliability so that they will be eligible for cost recovery using standard regulatory procedures.

The main contribution of this paper is to show that determining the net system benefit of a transmission line correctly should consider its value for maintaining reliability as well as its value for transferring power. Using congestion rents only to measure the net benefit of a line may be very misleading. The empirical analysis in this paper demonstrates how different specifications of the level and uncertainty of wind generation affect the true economic values of specific transmission lines.

The empirical analysis uses a Security Constrained Optimal Power Flow (SCOPF) model that has been developed by PSERC researchers at Cornell together with a test network. The operating objective is to minimize the expected cost of meeting load in a selected hour over a discrete set of possible system states with known probabilities of occurring. The system states include major equipment failures (contingencies) with low probabilities of occurring and higher probability intact states with four different levels of potential wind generation that reflect the uncertainty of this source of generation. For a given hour, the model is solved separately for three different wind forecasts, with known probabilities of occurring, and the expected outcomes are the weighted averages for the three wind forecasts and the different system states (including contingencies) for each forecast. Annual results are determined by summing the results for 100 different levels of load that represent the load duration curve. Even though the amount of installed wind capacity for a given wind specification remains the same throughout the year, the forecasts of potential wind generation vary by hour.

The optimization is subject to the physical and flow constraints of an electric grid (Kirchhoff's laws) and also to the ramping capabilities of individual generating units to ensure that the optimum levels of dispatch in all system states are attainable. The difference between the maximum dispatch and the expected dispatch for any generating unit measures the amount of capacity committed for reserves in a given hour. As a result, the model determines the quantities of reserves endogenously, and in general, more uncertainty about the system states leads to more reserves being committed to maintain the reliability of supply.

The analysis considers four increasing levels of wind capacity in a rural region that are associated with retirements of existing coal capacity ${ }^{11}$ in the same region. For each specification of wind capacity, there are four realizations of potential wind generation for each hour. There are also three different specifications of the uncertainty of wind generation. The realizations for Normal wind are derived from observed data for a wind farm. For Nice wind, there is less uncertainty and the range of the realizations is truncated for each forecast to reflect the mitigating effects of co-located storage capacity. The realizations for Nasty wind are identical to Normal wind but all of the potential wind generation must be dispatched under a must-take contract. With Normal and Nice wind,

${ }^{11} 3 \mathrm{MW}$ of wind capacity replaces $1 \mathrm{MW}$ of coal capacity. 
some potential wind generation can be spilled, and this typically occurs for the high realizations of potential wind generation to reduce the amount of reserve capacity that is needed for ramping.

The results show that the implied nodal prices for an individual transmission line (see Eq. (3)) can vary dramatically in different system states, particularly when contingencies occur (Figure 5). Even though the nodal prices for intact system states appear to be similar in (Figure 5), they are actually substantially different for some transmission lines (Figure 6). By combining these nodal prices with the flows in different system states the congestion revenues can be determined ${ }^{12}$ Using the occurrence probabilities for each system state, the weighted sum is an estimate of the expected congestion revenue for a given level of load. Summing over the 100 levels of load gives the expected annual congestion revenue for each transmission line. This annual revenue is computed in two parts. The first part considers only intact system states and measures the revenue from transferring power. The second part considers only contingency states and measures the revenue from maintaining reliability.

The expected annual congestion revenues for the individual transmission lines in Figure 7 show that the amounts are modest for most lines, but two lines stand out with high positive values. The revenue for transferring power on Line 15 and the revenue for reliability on Line 22 are both much larger than they are for other lines. Since Lines 15 and 22 are so important for operating the network, the remainder of the analysis focuses on showing how changing their capacities affects the expected total annual system cost for different levels and qualities wind generation. This annual system cost includes both the operating (fuel) costs of generation and the capital costs of generating capacity and transmission. Since the net revenues above out-of-pocket operating costs paid to generators in the wholesale market and the congestion revenues paid to transmission owners are generally insufficient to cover their capital costs, they also get paid "missing money" by regulators to cover the full cost of capital 13

The results for Normal and Nice wind are quite similar and generally consistent with our prior expectations. Adding transfer capacity by upgrading Line 15 lowers total annual system costs (Payments by Customers in Figures 8 and 9). However, the lower uncertainty of Nice wind affects the high levels of wind penetration because less of the potential wind generation is spilled, and as a result, the operating costs are lower. Adding more transfer capacity by upgrading Line 15 reduces costs slightly by spilling less wind generation, particularly at high penetrations of wind capacity. Making the network less reliable by downgrading Line 22 increases total annual costs slightly, as expected, but the relationship

\footnotetext{
${ }^{12}$ Congestion revenue for an individual transmission line can be negative in some system states and positive in others. This phenomenon is caused by the inflexibility of the network in the sense that the same network topology operates over a wide range of different system states (e.g., levels of load and wind generation).

${ }^{13}$ In most deregulated regions, capacity markets provide additional revenue for generators and the missing money for transmission owners is still determined using standard regulatory procedures.
} 
with the level of wind penetration is not as clear as it is with upgrading Line 15. Overall, the underlying feature of both Normal and Nice wind is that it is always possible to spill potential wind generation and avoid situations in which lowering the operating costs by dispatching more wind generation leads to much higher costs for balancing network flows and maintaining reliability. This is the reason why the system costs for high levels of Normal wind are so similar. There is no penalty for spilling high levels of Normal wind. In contrast, the must-take contract implied by Nasty wind means that spilling wind is not allowed, and accommodating high levels of Nasty wind creates a lot of stress on the network.

Consequently, the results for Nasty wind are very different from the results for Normal and Nice wind. In fact, the total annual costs increase with higher penetrations of Nasty wind even though more wind generation is being dispatched. The reason is that high penetrations of Nasty wind increase operating costs because more expensive units must be dispatched to balance network flows. As a result, adding transfer capacity by upgrading Line 15 is very valuable for Nasty wind compared to Normal and Nice wind because it reduces the stress on the network in system states when there is a lot of potential wind generation relative to the level of load. However, the effects of reducing network reliability by downgrading Line 22 are less clear. In general, downgrading Line 22 increases total annual system costs, as expected, but at the highest level of penetration, this system cost is actually lower.

The overall conclusion of the analysis for regulators is that although there may be situations in which reductions in the congestion revenues for a specific transmission line can justify investing in an upgrade, this is generally not the case in a meshed network ${ }^{14}$ Upgrading a transmission line on a meshed network may also have substantial implications for the economic cost of meeting reliability standards that should not be ignored. These reliability effects can reduce the total annual system costs by reducing load shedding in contingency states, spilling less potential wind generation and reducing the capital costs of the reserve generating capacity needed to maintain System Adequacy. Consequently, it is generally misleading to rely on the estimated reductions in the expected congestion revenues to set priorities for investing in transmission upgrades. The real situation is more complicated. Some form of planning process is needed to determine that there really are net system benefits for the network from a specific investment in new transmission. This evaluation should cover the full range of operating conditions, consider both operating and capital costs and ensure that reliability standards are maintained.

\footnotetext{
${ }^{14}$ For example, the Eastern Interconnection in the US is predominately meshed and the issues raised in this paper are directly relevant. In contrast, the Western Interconnection is predominantly radial, and transferring power is the primary role of the major transmission lines from the Pacific Northwest to California.
} 


\section{Acknowledgements}

The authors would like to thank Ray D. Zimmerman, Carlos E. MurilloSanchez, Luis F. Zuluaga, Carlo A. Bollino, Mary E. Daily, Wooyoung Jeon, Richard E. Schuler, Aleksandra Janjic, and Steven Gabriel, as well as participants at the Eastern and Western Rutgers Conferences organized by the Center for Research in Regulated Industries, the Advances in Energy Economics Research session of the Allied Social Science Associations annual meeting, and the Lehigh University and Carnegie Mellon University seminars for their comments and input. We also thank the editor and three anonymous reviewers for their constructive suggestions. This research was supported by the National Science Foundation through the CyberSEES grant \#1442858, the US Department of Energy through the Consortium for Electric Reliability Technology Solutions (CERTS) and the Power Systems Engineering Research Center (PSERC). The authors are responsible for all conclusions presented in the article, and the views expressed have not been endorsed by the sponsoring agencies.

\section{References}

Allen, E., Lang, J., Ilic, M., Aug. 2008. A combined equivalenced-electric, economic, and market representation of the northeastern power coordinating council u.s. electric power system. Power Systems, IEEE Transactions on $23(3), 896-907$.

Alsac, O., Stott, B., May 1974. Optimal load flow with steady-state security. Power Apparatus and Systems, IEEE Transactions on PAS-93 (3), 745 -751.

Anderson, C. L., Cardell, J. B., 2008. Reducing the variability of wind power generation for participation in day ahead electricity markets. In: HICSS '08: Proceedings of the 41st Annual Hawaii International Conference on System Sciences. IEEE Computer Society, Washington, DC, USA, p. 178.

Baldick, R., Kahn, E., nov 1993. Transmission planning issues in a competitive economic environment. Power Systems, IEEE Transactions on 8 (4), 1497 -1503 .

Benders, J. F., 1962. Partitioning procedures for solving mixedvariables programming problems. Numerische Mathematik 4, 238-252, 10.1007/BF01386316.

URL http://dx.doi.org/10.1007/BF01386316

Blumsack, S., Ilic, M., Lave, L., 24-28 2007a. Separability and independence of congestion and reliability: Theory and simulations. In: Power Engineering Society General Meeting, 2007. IEEE. pp. $1-10$.

Blumsack, S., Lave, L. B., Ilic, M., 2007b. A quantitative analysis of the relationship between congestion and reliability in electric power networks. The Energy Journal 28 (4), 73-100.

URL http://ideas.repec.org/a/aen/journl/2007v28-04-a04.html 
Borenstein, S., Bushnell, J., Stoft, S., 2000. The competitive effects of transmission capacity in a deregulated electricity industry. The RAND Journal of Economics $31(2)$.

Bowring, J., 2012. State of the market report for PJM. Tech. rep., Monitoring Analytics, LLC.

URL https://www.pjm.com/documents/reports/ state-of-market-reports.aspx

Brint, J., 2012. PJM changing rules for up-to congestion transactions. Platts. URL http://www.platts . com/RSSFeedDetailedNews/RSSFeed/ ElectricPower/8814045

Cardell, J. B., Hitt, C. C., Hogan, W. W., 1997. Market power and strategic interaction in electricity networks. Resource and Energy Economics 19 (1-2), $109-137$.

URL http://www.sciencedirect.com/science/article/pii/ S0928765597000067

Chen, J., Mount, T. D., Thorp, J. S., Thomas, R. J., 2005. Location-based scheduling and pricing for energy and reserves: a responsive reserve market proposal. Decis. Support Syst. 40 (3-4), 563-577.

Choi, J., Mount, T., Thomas, R., nov. 2007. Transmission expansion planning using contingency criteria. Power Systems, IEEE Transactions on 22 (4), 2249 -2261 .

DOE, May 2008. 20\% wind energy by 2030. Tech. Rep. NA, U.S. Department of Energy (DOE).

URL http://www1 . eere . energy .gov/windandhydro/pdfs/41869.pdf

DOE, 2009. National electric transmission congestion study. Tech. rep., DOE. URL http://congestion09.anl.gov/documents/docs/congestion_ study_2009.pdf

Downward, A., 2010. Carbon charges in electricity markets with strategic behavior and transmission. Energy Journal 31 (4), 159 - 166.

URL http://search.ebscohost.com.proxy.library.cornell.edu/ login. aspx?direct=true\&db=bth\&AN=54353664\&site=ehost-live

EIA, E. I. A., 2014. Annual energy outlook. Tech. rep., Energy Information Administration. URL http://www .eia.gov/forecasts/aeo/

Eto, J., 2002. The national transmission grid study. Tech. rep., Lawrence Berkeley National Laboratory. URL http://certs . lbl.gov/certs-rtinakey-ntgs .html 
Ferrero, R., Shahidehpour, S., Ramesh, V., Aug. 1997. Transaction analysis in deregulated power systems using game theory. Power Systems, IEEE Transactions on 12 (3), $1340-1347$.

Genc, T. S., Thille, H., 2011. Investment in electricity markets with asymmetric technologies. Energy Economics 33 (3), 379 - 387.

URL http://www.sciencedirect.com/science/article/pii/ S0140988310001258

Henderson, T., Crowcroft, J., Bhatti, S., 2001. Congestion pricing: paying your way in communication networks. IEEE Internet Computing 5, 85-89. URL http://in3.dem.ist.utl.pt/master/03telecompolicy/lec_11_2. pdf

Hogan, W. W., 1992. Contract networks for electric power transmission. Journal of Regulatory Economics 4 (3), $211-242$.

URL http://search.ebscohost.com/login.aspx?direct=true\&db=bth\& AN $=16580807 \&$ site $=$ ehost - live

ISONE, 2004. Regional transmission expansion plan. Tech. rep., ISONE. URL http://www.iso-ne.com/trans/rsp/2004/RTEP04_Exec_and_ Summary_Report_Final_Publication.pdf

ISONE, 2012. Annual markets report. Tech. rep., ISONE.

URL http://www.iso-ne.com/markets/mkt_anlys_rpts/annl_mkt_rpts/ 2011/2011_amr_final_051512.pdf

Joskow, P., Tirole, J., 2005. Merchant transmission investment. Journal of Industrial Economics 53 (2), 233 - 264 .

URL http://ideas.repec.org/a/bla/jindec/v53y2005i2p233-264.html

Joskow, P. L., Winter 2012. Creating a smarter u.s. electricity grid. Journal of Economic Perspectives 26 (1), 29-48.

URL http: //www . aeaweb .org/articles . php?doi=10.1257/jep.26.1.29

Lamadrid, A., Maneevitjit, S., Mount, T., Murillo-Sanchez, C., Thomas, R., Zimmerman, R., 2008. A "superopf" framework. Tech. rep., CERTS.

Lamadrid, A., Mount, T., Jeon, W., Lu, H., 2015/02/05 2014. Is deferrable demand an effective alternative to upgrading transmission capacity? Journal of Energy Engineering, B4014005.

URL http://dx .doi .org/10.1061/(ASCE)EY.1943-7897.0000182

Lamadrid, A. J., Mount, T., 2012. Ancillary services in systems with high penetrations of renewable energy sources, the case of ramping. Energy Economics 34 (6), 1959 - 1971.

URL http://www.sciencedirect.com/science/article/pii/ S0140988312001818 
Lawton, L., Sullivan, M., Van Liere, K., Katz, A., Eto, J., 2003. A framework and review of customer outage costs: Integration and analysis of electric utility outage cost surveys. Tech. rep., U.S. Department of Energy, Washington DC.

Lin, J., 27-29 2009. Market-based transmission planning model in PJM electricity market. In: EEM 2009. 6th International Conference on the European Energy Market. pp. $1-6$.

Lobo, M. S., Vandenberghe, L., Boyd, S., Lebret, H., 1998. Applications of second-order cone programming. Linear Algebra and its Applications 284 (13), 193 - 228, international Linear Algebra Society (ILAS) Symposium on Fast Algorithms for Control, Signals and Image Processing. URL http://www.sciencedirect.com/science/article/pii/ S0024379598100320

MacKie-Mason, J. K., Varian, H. R., 1995. Public Access to the Internet, 1995. MIT Press, Ch. Pricing the Internet, pp. 269-314.

Magnanti, T. L., Wong, R. T., 1984. Network design and transportation planning: Models and algorithms. Transportation Science 18 (1), 1.

URL http://search.ebscohost.com.proxy.library.cornell.edu/ login . aspx?direct=true\&db=a2h\&AN=4476570\&site=ehost-live

Mount, T., Lamadrid, A., Maneevitjit, S., Thomas, B., Zimmerman, R., Jan. 2009. Evaluating the net benefits of investing in new wind and transmission capacity on a network. In: System Sciences, 2009. HICSS '09. 42nd Hawaii International Conference on. http://www.computer.org/portal/web/csdl/doi/10.1109/HICSS.2009.716, pp. $1-10$.

Mount, T., Lamadrid, A., Thomas, B., Zimmerman, R., March 2010. The system costs of integrating wind generation into wholesale electricity markets. In: http://www.ece.cmu.edu/ electriconf/mount_cmu2010f.pdf (Ed.), Sixth Annual Carnegie Mellon Conference on the Electricity Industry. Carnegie Mellon University, Pittsburgh.

Mount, T., Maneevitjit, S., Lamadrid, A., Thomas, B., Zimmerman, R., 2012. The hidden system costs of wind generation in a deregulated electricity market. The Energy Journal 33 (1), 161-186.

Munoz, F., Sauma, E., Hobbs, B., 2013. Approximations in power transmission planning: implications for the cost and performance of renewable portfolio standards. Journal of Regulatory Economics 43 (3), 305-338.

URL http://dx.doi.org/10.1007/s11149-013-9209-8

Murillo-Sanchez, C. E., Zimmerman, R. D., Anderson, C. L., Thomas, R. J., 2013. A stochastic, contingency-based security-constrained optimal power flow for the procurement of energy and distributed reserve. Decision Support 
Systems $56(0), 1-10$.

URL http://www.sciencedirect.com/science/article/pii/ S0167923613001152

NERC, 2013. Reliability Standards for the Bulk Electric Systems of North America. North American Electric Reliability Corporation, 3353 Peachtree Road NE Suite 600, North Tower, Atlanta, GA 30326.

URL http://www.nerc.com/docs/standards/rs/Reliability_ Standards_Complete_Set.pdf

NREL, January 2010. Eastern wind integration and transmission study. Tech. rep., EnerNex Corporation, The National Renewable Energy Laboratory, 1617 Cole Boulevard, Golden, Colorado 80401.

Oren, S. S., 1997. Economic inefficiency of passive transmission rights in congested electricity systems with competitive generation. The Energy Journal 18 (1), 63-84.

URL http://ideas.repec.org/a/aen/journl/1997v18-01-a03.html

Peevey, M. R., Simon, T. A., Florio, M. P., Sandoval, C. J., Ferron, M. J., 2011. Cpuc public agenda 3281. Tech. rep., CPUC.

PJM, 2012. Up-to transactions history, benefits and analysis. CAM Energy LLC, City Power Marketing LLC, Dyon LLC, Great Bay Energy LLC, Monterey Enterprises LLC, Red Wolf Energy Trading LLC, SESCO Enterprises LLC, Twin Cities Power LLC, West Oaks Energy LLC and XO Energy Companies, PJM.

Sauma, E., Oren, S., nov. 2007. Economic criteria for planning transmission investment in restructured electricity markets. Power Systems, IEEE Transactions on $22(4), 1394-1405$.

Sauma, E. E., Oren, S. S., 2009. Do generation firms in restructured electricity markets have incentives to support social-welfare-improving transmission investments? Energy Economics 31 (5), 676 - 689.

URL http://www.sciencedirect.com/science/article/pii/ S0140988309000218

Schuler, R., 2012. Pricing the use of capital-intensive infrastructure over time and efficient capacity expansion: illustrations for electric transmission investment. Journal of Regulatory Economics 41 (1), 80-99.

URL http://dx.doi.org/10.1007/s11149-011-9176-x

Spiecker, S., Weber, C., july 2011. Integration of fluctuating renewable energy; a german case study. In: Power and Energy Society General Meeting, 2011 IEEE. pp. $1-10$.

Stoft, S., 1997. Transmission rights and wrongs. The Electricity Journal 10 (8), $91-95$. 
URL

http://www.sciencedirect.com/science/article/ B6VSS-453CB8M-91/2/2b7023ba492e33e58b73130ed47ff55a

Thomas, R., Mount, T., Schuler, R., Schulze, W., Zimmerman, R., 2006. Markets for reactive power and reliability: A white paper. Tech. rep., E3RG.

Thomas, R., Murillo-Sanchez, C., Zimmerman, R., July 2008. An advanced security constrained opf that produces correct market-based pricing. In: Power and Energy Society General Meeting - Conversion and Delivery of Electrical Energy in the 21st Century, 2008 IEEE. pp. 1-6.

Troy, N., Flynn, D., Milligan, M., O’Malley, M., 2012. Unit commitment with dynamic cycling costs. Power Systems, IEEE Transactions on PP (99), 1.

USCongress, 2005. Energy Policy Act. 109th Congress of the United States of America.

USCongress, 2008. Emergency Economic Stabilization Act of 2008. US House of Representatives, Washington, DC, USA.

van der Weijde, A. H., Hobbs, B. F., 2012. The economics of planning electricity transmission to accommodate renewables: Using two-stage optimisation to evaluate flexibility and the cost of disregarding uncertainty. Energy Economics 34 (6), $2089-2101$.

URL http://www.sciencedirect.com/science/article/pii/ S0140988312000436

Vardi, J., Zahavi, J., Avi-Itzhak, B., 1977. The combined load duration curve and its derivation. Power Apparatus and Systems, IEEE Transactions on $96(3), 978-983$.

Wu, F., Varaiya, P., Spiller, P., Oren, S., 1996. Folk theorems on transmission access: Proofs and counterexamples. Journal of Regulatory Economics 10 (1), 5-23, 10.1007/BF00133356.

URL http: //dx .doi.org/10.1007/BF00133356

Yu, C.-N., Leotard, J.-P., Ilic, M., 1999. Dynamics of transmission provision in a competitive power industry. Discrete Event Dynamic Systems 9, 351-388. URL http: //dx .doi .org/10.1023/A\%3A1008350416476

\section{Appendix A Nomenclature}

$\begin{array}{ll}\mathscr{K} & \text { Set of all contingencies, } n_{c} \text { elements. } \\ \mathscr{B} & \text { Set of all buses, } n_{b} \text { elements. } \\ \mathscr{G} & \text { Set of generating units, } n_{g} \text { elements. } \\ \theta, V & \text { Vector of } n_{b} \text { bus voltage angles and magnitudes in post-contingency } \\ & \text { state. }\end{array}$


$P, Q \quad$ Vector of $n_{g}$ active and reactive power injections in post contingency state.

$P^{+}, Q^{+} \quad$ Vector of $n_{g}$ active and reactive upward deviations from contract.

$C_{P_{i}}(\cdot), C_{Q_{i}}(\cdot)$ Cost for $i$ active and reactive injections.

$C_{P_{i}}^{+}(\cdot), C_{Q_{i}}^{+}(\cdot)$ Cost of active and reactive incremental injections from previous stage.

$C_{P_{i}}^{-}(\cdot), C_{Q_{i}}^{-}(\cdot)$ Cost of active and reactive decremental injections from previous stage.

$p_{c i}^{t-1}, q_{c i}^{t-1}$ Contracted amounts of active and reactive power.

$r_{P i}^{+, t}, r_{Q i}^{+, t} \quad$ Upside active and reactive set reserves.

$R_{P i}^{P H Y S+}, R_{P i}^{P H Y S-}$ Physical ramp rate capabilities

$\pi_{k} \quad$ Probability of contingency $k$. 